\title{
The integumental appendages of the turtle shell: An evo-devo perspective
}

\section{Moustakas-Verho, Jacqueline}

\section{5}

Moustakas-Verho , J \& Cherepanov , G 2015 , ' The integumental appendages of the turtle shell: An evo-devo perspective ' , Journal of Experimental Zoology. Part B: Molecular and Developmental Evolution , vol. 324 , no. 3 , 22619 , pp. 221-229 . https://doi.org/10.1002/jez.b.22619

http://hdl.handle.net/10138/223804

https://doi.org/10.1002/jez.b.22619

acceptedVersion

Downloaded from Helda, University of Helsinki institutional repository.

This is an electronic reprint of the original article.

This reprint may differ from the original in pagination and typographic detail.

Please cite the original version. 


\title{
The Integumental Appendages of the Turtle Shell: An Evo-Devo Perspective
}

\author{
JACQUELINE E. MOUSTAKAS-VERHO ${ }^{1 *}$ \\ AND GENNADII 0. CHEREPANOV ${ }^{2}$ \\ ${ }^{1}$ Institute of Biotechnology, University of Helsinki, Helsinki, Finland \\ ${ }^{2}$ Department of Vertebrate Zoology, Faculty of Biology, St. Petersburg State University, \\ St. Petersburg, Russia
}

$\begin{array}{ll}\text { ABSTRACT } & \text { The turtle shell is composed of dorsal armor (carapace) and ventral armor (plastron) covered by a } \\ \text { keratinized epithelium. There are two epithelial appendages of the turtle shell: scutes (large } \\ \text { epidermal shields separated by furrows and forming a unique mosaic) and tubercles (numerous } \\ \text { small epidermal bumps located on the carapaces of some species). In our perspective, we take a } \\ \text { synthetic, comparative approach to consider the homology and evolution of these integumental } \\ \text { appendages. Scutes have been more intensively studied, as they are autapomorphic for turtles and } \\ \text { can be diagnostic taxonomically. Their pattern of tessellation is stable phylogenetically, but labile } \\ \text { in the individual. We discuss the history of developmental investigations of these structures and } \\ \text { hypotheses of evolutionary and anomalous variation. In our estimation, the scutes of the turtle } \\ \text { shell are an evolutionary novelty, whereas the tubercles found on the shells of some turtles are } \\ \text { homologous to reptilian scales. J. Exp. Zool. (Mol. Dev. Evol.) 324B:221-229, 2015. } \\ \text { C 2015 Wiley Periodicals, Inc. } \\ \text { How to cite this article: Moustakas-Verho JE, Cherepanov G0. 2015. The integumental } \\ \text { J. Exp. Zool. } \\ \text { (Mol. Dev. Evol.) } \\ \begin{array}{l}\text { 324B:221-229, } \\ \text { 2015 }\end{array}\end{array}$

\section{EVOLUTIONARY ORIGIN AND DEVELOPMENT OF TURTLE SCUTES}

The evolutionary origin and phylogenetic affinities of turtles are still under debate (Reisz and Laurin, '91; Laurin and Reisz, '95; DeBraga and Rieppel, '97; Lee, '97; Rieppel and Reisz, '99; Hirasawa et al., 2013; Lyson et al., 2013; Shaffer et al., 2013; Wang et al., 2013; Crawford et al., 2014; Thomson et al., 2014), but undoubtedly, turtles evolved from reptilian stock (reptiles defined as turtles, lepidosaurs, archosaurs, including birds, and all descendants of their most recent common ancestor (Gauthier et al. '88)). Integumental appendages of reptiles include scales, scutes, tubercles, protofeathers, and feathers. Turtles have two types of epidermal derivatives on their shell: large horny scutes (large epidermal shields separated by furrows and forming a unique mosaic) and small horny tubercles (numerous small epidermal bumps located on the carapaces of some species; Figs. 1, 2, and 4; Goette, '99; Lange, '31). Our perspective focuses primarily on the scutes. Scutes were present on the shells of the oldest known turtles, Odontochelys (Lyson et al., 2014) and Proganochelys (Gaffney, '90). Turtle scutes cover the turtle shell as a keratinized epithelium in a mosaic pattern, or pholidosis.
Turtles can often be recognized by the pattern of scutes, or lack thereof, on their shell. Most hard-shelled turtles have 38 scutes in the carapace, and 16 in the plastron. The carapacial scutes are grouped into marginal (12 pairs), costal (also called pleural or lateral; 4 pairs), vertebral (5 unpaired), and a nuchal scute (Fig. 1). In the plastron, there are six pairs of plastral and two pairs of inframarginal scutes.

Though scutes and scales differ greatly in their morphology from feathers, hair, teeth, and exocrine glands, they are all derivatives of the ectoderm and share some similarities in their

Grant sponsor: St. Petersburg State University; grant number: 0.38.292.2015.

${ }^{*}$ Correspondence to: Jacqueline E. Moustakas-Verho, Institute of Biotechnology, University of Helsinki, Helsinki 00014, Finland.

E-mail: Jacqueline.Moustakas@helsinki.fi

Received 18 December 2014; Accepted 26 February 2015

DOI: $10.1002 / j e z . b .22619$

Published online in Wiley Online Library

(wileyonlinelibrary.com). 


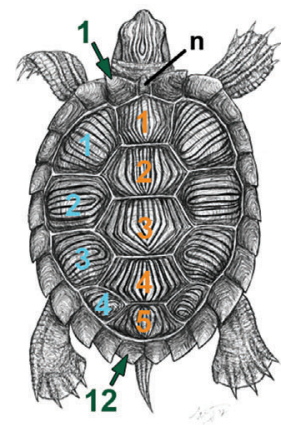

Trachemys scripta

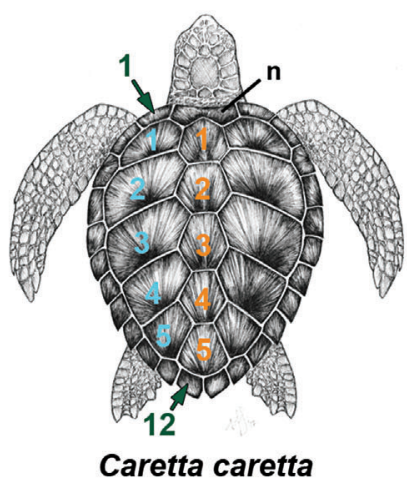

Caretta caretta
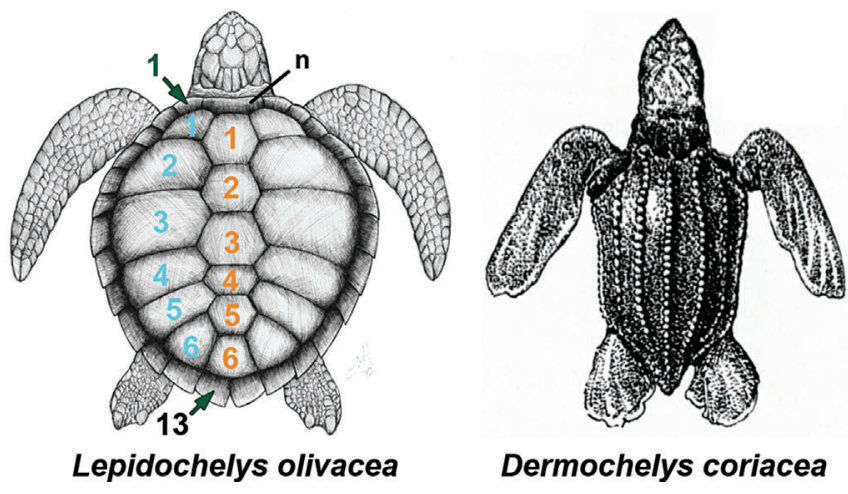

Dermochelys coriacea

Figure 1. Natural interspecific variation in the turtle shell epidermis. (A) Trachemys scripta shows the most common pattern of turtle scutes (12 pairs of marginals, 4 pairs of costals, 5 vertebrals, and 1 nuchal). (B) Caretta caretta has an additional pair of costal scutes. (C) Lepidochelys olivacea has additional vertebral, costal, and marginal scutes, though the numbers vary among individuals. (D) Instead of scutes, Dermochelys coriacea has a leathery skin with longitudinal rows of horny tubercles embedded with miniscule osteoderms. Costal scutes are numbered in blue, vertebrals in orange, marginals in green; $n$, nuchal. T. scripta, $C$. caretta, L. olivacea illustrations by Tiff Shao from Moustakas et al. (2014); D. coriacea illustration from Obst ('86).

early development. Investigations of how turtle scutes and tubercles are formed have, therefore, compared their morphogenesis to that of other ectodermal organs. Archosaurian (crocodilian and avian) scales and turtle scutes develop from local epithelial thickenings called placodes, though the scales of lizards and snakes (Lepidosauria) develop without placodes as skin folds (Maderson, '65; Sawyer, '72; Harris et al., 2002; Cherepanov, '89, 2006; Alibardi and Minelli, 2014; MoustakasVerho et al., 2014; we do not consider crocodilian osteoderms, which have been called scutes by some workers, to be homologous to the skin appendages we discuss). Scute placodes form earlier in embryonic development than scales and tubercles (Cherepanov, 2005; Moustakas-Verho et al., 2014), slightly after the appearance of the carapacial ridge (CR), a protrusion of epithelium and dermatomal mesenchyme on the dorsolateral trunk of the embryo that is the first morphological indication of turtle shell development (Ruckes '29; Burke '89; Moustakas 2008). The marginal scute placodes form first along the CR, followed by the costals; the vertebral and nuchal placodes appear last and develop as paired placodes that will fuse subsequently to form individual scutes (Cherepanov, '89, 2002, 2005, 2006; Moustakas-Verho et al., 2014). The carapacial placodes, therefore, develop from the periphery (beginning at the $\mathrm{CR}$ ) towards the midline (Fig. 2). Plastron scute development begins after carapacial scute development is under way, with plastral placodes appearing symmetrically at the periphery of the abdominal shield (Cherepanov, 2002, 2005, 2006; Moustakas-Verho et al., 2014).

Furrows, also called seams, develop following the establishment of the array of scute primordia. Furrows delineate the margins of scutes and can leave a depression, called a sulcus, on the underlying bones. They first form along the midline, between presumptive vertebral scutes, then between presumptive costal scutes. These furrows, therefore, develop centrifugally from the center towards the periphery (Fig. 2). In contrast, the furrows between the marginal scutes and the plastral scutes develop from the periphery of the shell and expand centripetally (Cherepanov, 2002, 2005, 2006, 2014). This radial growth of the scutes distinguishes them from scales and feathers, which grow proximo-distally.

\section{SCUTE PATTERNING}

Several lines of evidence suggest that the locations where placodes appear on the developing turtle carapace are determined by the somites, or primary body segmentation. The examination of histological sections has shown that placodes develop along depressions of the integument formed by the myosepta (Cherepanov, '89, 2002, 2005, 2006, 2014) and in areas of overlapping Shh and Bmp2 expression (Moustakas-Verho et al., 2014; Fig. 3). The marginal placodes form in 12 septal depressions along each CR, and the four pairs of costal placodes form symmetrically on the dorsolateral side of the trunk in the areas of even (II, IV, VI, and VIII) transverse thoracic myosepta (the myoseptum in the area of the formation of the first rib is regarded as the first thoracic myoseptum). The vertebral placodes form in the areas of odd transverse thoracic myosepta (I, III, V, VII, and IX), i.e., in staggered rows with the costal placodes (Cherepanov, '89, 2002, 2005, 2006; Fig. 3). The plastral scute placodes do not form opposite myosepta; however, the peripheral region of the plastron where these placodes will form has traces of somatic segmentation (Guyot et al., '94). 

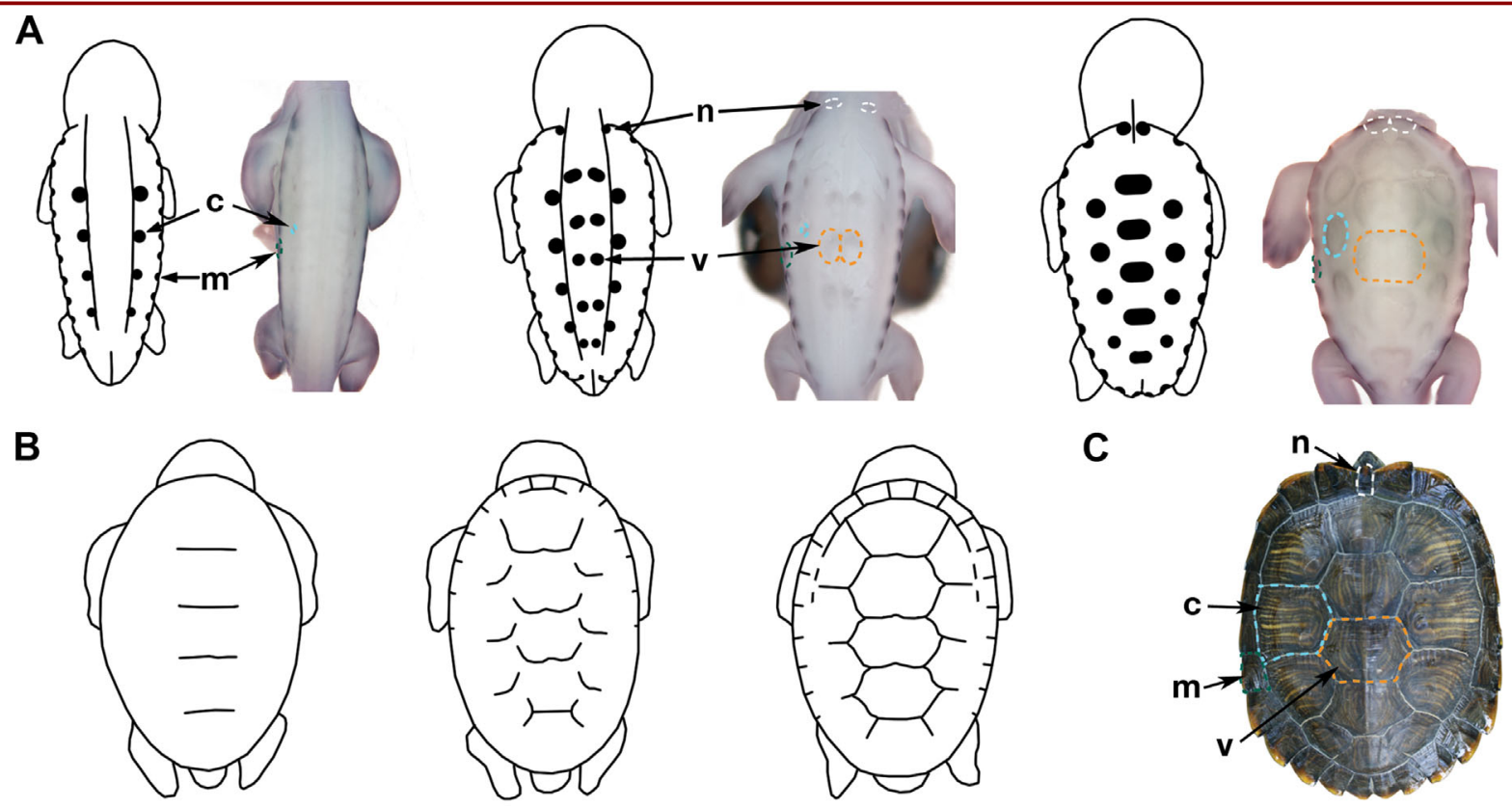

Figure 2. (A) Dynamics of carapacial scute formation, reconstructed from histological sections (modified from Cherepanov, '89, 2002, 2005, 2006,2014 ) and visualized with Bmp2 expression (modified from Moustakas et al., 2014; m, marginal, green outline; $c_{1}$ costal, blue outline; $v_{1}$ vertebral, orange outline; $n$, nuchal, white outline). (B) Dynamics of carapacial furrow formation (modified from Cherepanov, '85, 2002, 2005, 2006, 2014). (C) Final scute architecture exemplified by Trachemys scripta adult specimen (photo credit of adult $T$. scripta: Bob Smither).

The results of extirpation experiments on the common snapping turtle, Chelydra serpentina, suggest that altering the configuration of some carapacial scute placodes has an effect on the patterning of the others. Extirpation of several adjacent somites in Chelydra resulted in the loss of part of the shell, as well as alteration to the pattern of carapacial scutes (Yntema, '70). We further hypothesized that the pattern of scute induction and growth is generated by Turing mechanisms (MoustakasVerho et al., 2014). Starting from a pre-pattern of marginal scute placodes, as determined by the somites, we proposed that the formation of presumptive costal, vertebral, and nuchal scute signaling centers could be explained by a mathematical model that employs reaction-diffusion dynamics based on the basic Meinhardt-Gierer model (Gierer and Meinhardt, '72; MoustakasVerho et al., 2014). This first model, therefore, establishes the relative positions of the of scute placodes. A second reactiondiffusion system is induced by the placodal pattern and employs a traveling wave expansion from these scute signaling centers to generate the final scute architecture (Moustakas-Verho et al., 2014). These models are consistent with observations that the establishment of placodes proceeds from signaling centers at the periphery of the shell towards the midline, followed by the appositional growth of developing scutes and the formation of furrows (Cherepanov, 2002, 2005, 2006, 2014; MoustakasVerho et al., 2014).

The mathematical models of scute patterning are based on the periodic expression of key molecules in the domains of presumptive scutes (Moustakas-Verho et al., 2014). The molecular signals regulating the organogenesis of scutes and scales have been studied (Harris et al., 2002; Moustakas-Verho et al., 2014), as well as other ectodermal organ derivatives, including feathers, teeth, hair, and various exocrine glands (reviewed Pispa and Thesleff, 2003). Genes belonging to the transforming growth factor $\beta$ (Tgf $\beta)$, Hedgehog (Hh), and Fibroblast growth factor (Fgf) families are used reiteratively in the epithelialmesenchymal interactions that govern the morphogenesis of these organs (Jernvall and Thesleff, 2000; Harris et al., 2002; Pispa and Thesleff, 2003; Moustakas-Verho et al., 2014). The dynamic expression of several genes, including Bone Morphogenetic Protein-2 (Bmp2), Bmp4, the target gene Msx2, sonic hedgehog $(S h h)$, and the Bmp antagonist Gremlin, has been documented in the developing carapacial and plastral scutes of the hard-shelled slider turtle, Trachemys scripta (MoustakasVerho et al., 2014). The inhibition of hedgehog or Bmp signaling in developing Trachemys cultures resulted in the loss of scute placodes, showing that these pathways are necessary for the 
development of scutes. We furthermore observed that culturing embryos with an inhibitor of FGF receptor randomized carapacial placodal patterns, also implicating Fgf signaling in scute patterning (Moustakas-Verho et al., 2014). From these molecules, in vitro experiments where protein-coated beads were added to developing trunk cultures have evidenced SHH as potential activator and FGF4 as a potential inhibitor in the reactiondiffusion systems (Moustakas-Verho et al., 2014).

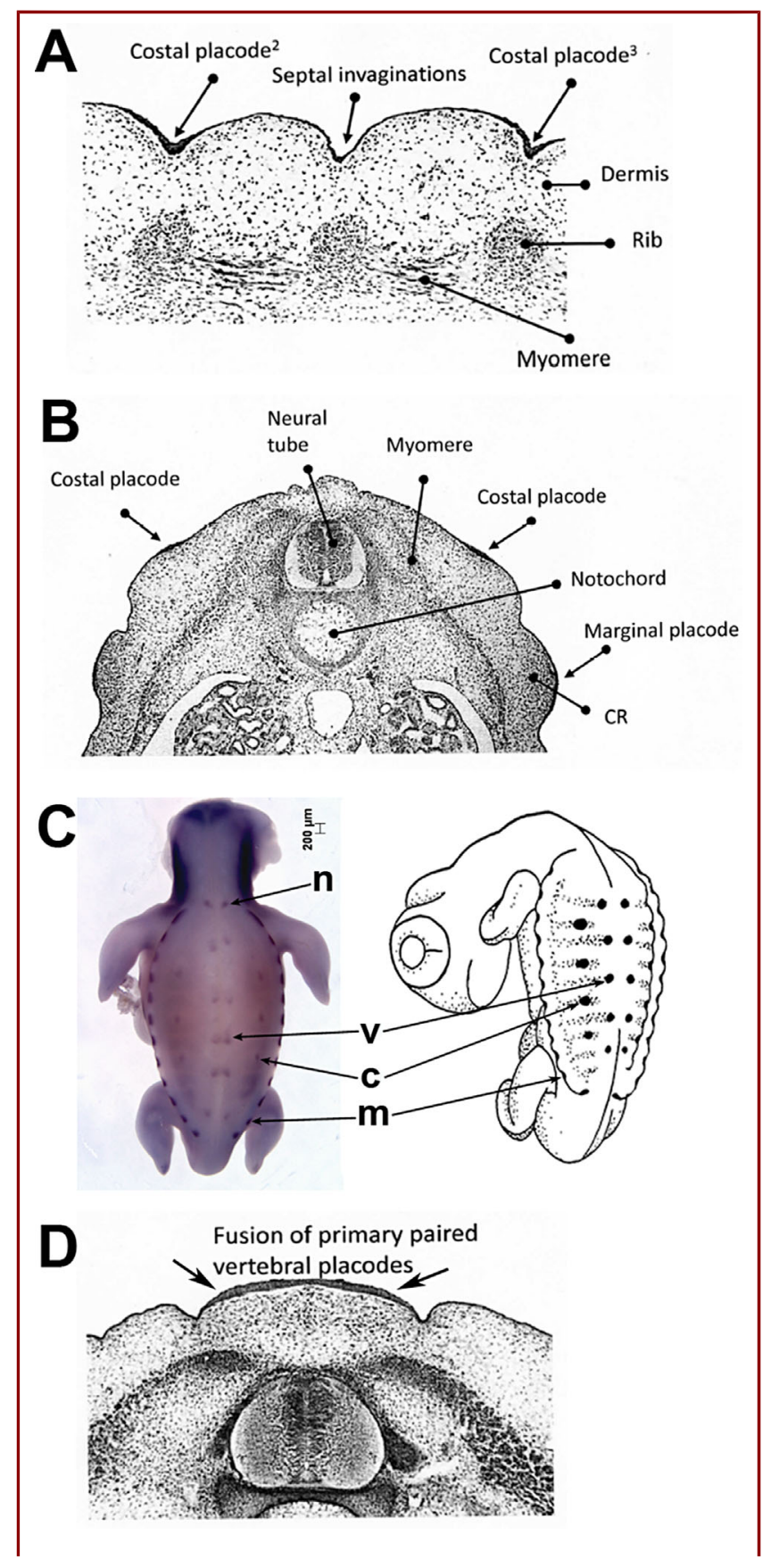

\section{EVOLUTIONARY VARIATION IN THE TURTLE SHELL'S EPIDERMIS}

Some sea turtles (Caretta caretta, Lepidochelys olivacea, and Lepidochelys kempii) have additional carapacial scutes (Fig. 1). C. caretta has five pairs of costal scutes, whereas Lepidochelys species have six to seven pairs of costal scutes and an additional vertebral scute. Both Caretta and Lepidochelys turtles vary in the number of marginal scutes that individuals have. Based on our mathematical models, we hypothesized that this natural, symmetrical variation is achieved by changing the length of the developing anterior-posterior axis (Moustakas-Verho et al., 2014). This is corroborated by observations that an increase in the number of marginal scutes has been shown to correlate with an increase in the number of peripheral plates of the bony carapace and myomeres, as well as an elongation of the shell (Lynn, '37; Cherepanov, 2005).

Scutes have been lost secondarily during evolution in certain freshwater (trionychid) and marine (Dermochelys) taxa, and reduced in the freshwater flatback sea turtle Natator. In a softshell turtle species that has been studied, Pelodiscus sinensis (formerly Trionyx sinensis), scute placodes do not form on the developing carapace or plastron, and the carapacial ridge epidermis is thickened uniformly along the entire length (Cherepanov, 2005; Moustakas-Verho et al., 2014). Genes that are expressed in a

Figure 3. The relationship of the developing scutes to the somites. (A-C) Following the formation of the carapacial ridges (CRs), the integument forms septal invaginations on the lateral sides of the body. The septal invaginations of the CRs have small local thickenings of the epidermis, the anlages of the marginal scutes (= marginal placodes), which are visible in histological sections. Four additional pairs of epidermal thickenings, which represent the anlages of the costal scutes (= costal placodes), are present above the CRs. They are positioned in II, IV, VI and VIII trunk septal invaginations, which are located opposite to the same numbered transverse myosepta. The marginal and costal placodes are separated by narrow and wide intervals of thin epidermis, respectively. Medial to the costal placodes, 5 pairs of new epidermal thickenings are visible, which represent the anlages of the vertebral scutes (= paired vertebral placodes). They are situated symmetrically on each side of the body, at the level of transverse trunk myosepta I, III, V, VII and IX; the left and right anlages are separated along the midline by a narrow band of thin epidermis. Paired nuchal placodes appear slightly later in the cranial part of the developing carapace. The relative positions of these anlages have been reconstructed with whole-mount in situ hybridization showing the expression of Shh at stage 16 and in an illustration by Cherepanov (2006) ( $m$, marginal placode; $c$, costal placode; $v$ vertebral placode; $n$, nuchal placode). (D) At later stages, the left and right anlages of the vertebral and nuchal placodes fuse in pairs along the midline of the carapace. 
segmented pattern in a hard-shelled turtle that develops scutes (Trachemys) are instead expressed in a continuous line along the CR in the scuteless turtle Pelodiscus (Moustakas-Verho et al., 2014). Furthermore, the CR of Pelodiscus resembles morphologically the CR of in vitro cultures of Trachemys embryos cultured with inhibitors of hedgehog or Bmp signaling, in which scute development is arrested (Moustakas-Verho et al., 2014). Shh is expressed in a pattern reminiscent of plastral placodes on the developing plastron of Pelodiscus (see Fig. 2A in MoustakasVerho et al., 2014); however, this expression appears to be vestigial, as placodes have not been observed in histological (Cherepanov, '92) or micro-computed tomography (microCT; Moustakas-Verho, unpublished observation) data.

Hard-shelled turtles have a hard $\beta$-keratin layer present in the epidermis (Baden and Maderson, '70; Maderson, '85; Alibardi and Thompson, '99; Alibardi, 2002). Also with the loss of scutes in softshell turtles is a correlated disappearance of the $\beta$ keratin layer in the epidermis. Most softshell turtles develop tubercles on their carapace (Webb, '62). The morphogenesis of tubercles in softshell turtles comprises the same stages as the reptilian scale: formation begins as tiny epidermal thickenings with a small accumulation of mesenchymal cells underneath, followed by proliferation of the epithelium and dermal papilla (symmetrical scale stage), then differential epithelial growth to obtain an asymmetric morphology (asymmetrical scale stage) (Fig. 4; Maderson, '65; Cherepanov, '92; Alibardi, '96). These tubercle-like scales persist in adult softshell turtles in the form of dermal papillae covered by an epidermis that is composed of $\alpha$ keratin (Cherepanov, '92).

Tubercles begin their formation at later stages of development than scutes. Tubercles are also seen on the shells of some hardshelled turtles that have scutes (for example, Testudo graeca, Emys orbicularis; Cherepanov, '85, 2005), but their development is restricted by the formation of the hard $\beta$-keratin layer. The development of these tubercles begins with the formation of tiny epidermal thickenings with an underlying mesenchymal condensation, and they differentiate up to the symmetrical scale stage (Fig. 4). In newborns, the dermal papillae are absent and the tubercles on the scutes are exclusively $\beta$-keratin horny elevations (Fig. 4; Cherepanov, '85, 2005).

\section{THE PHYLETIC STABILITY AND INDIVIDUAL INSTABILITY OF PATTERN}

Paleontological data show that almost all turtles have a universal scute mosaic pattern that has shown phyletic stability and little evolutionary variation. The earliest turtles, for example,

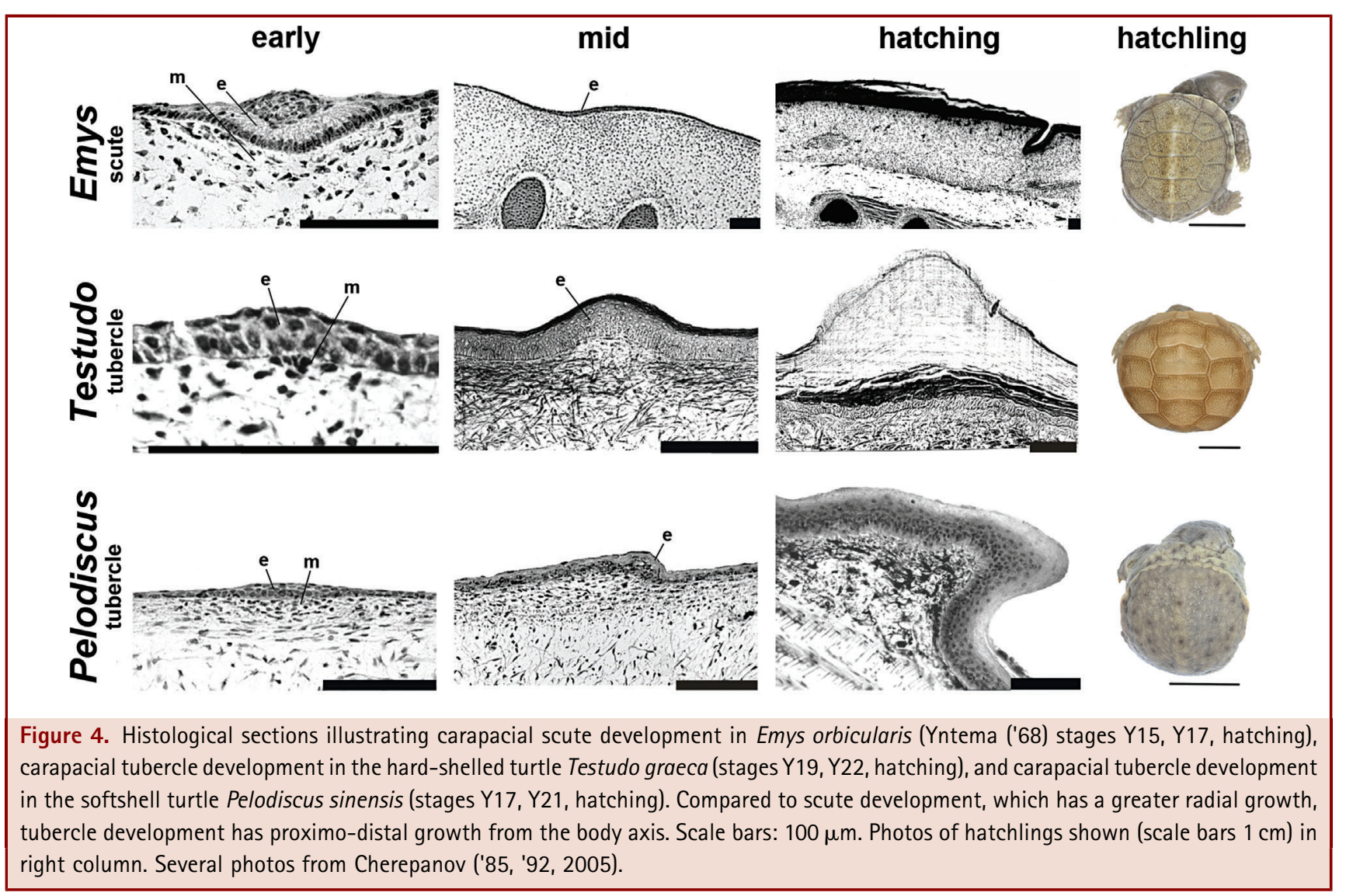

J. Exp. Zool. (Mol. Dev. Evol.) 

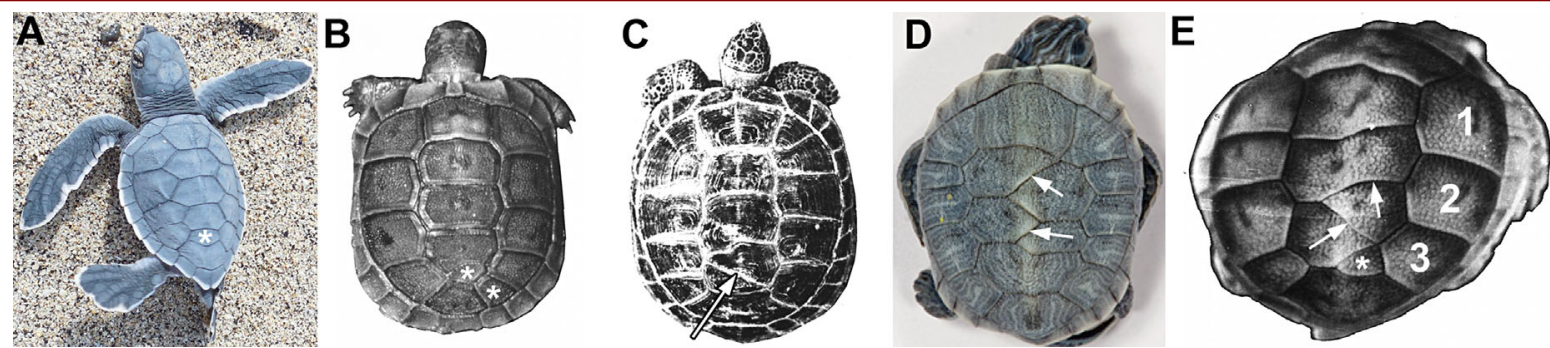

Figure 5. Carapacial scute anomalies. (A) Supernumerary vertebral scute (asterisk) in Chelonia mydas (photo credit: Dan Mulcahy). (B) Supernumerary costal and vertebral scutes (asterisks) in Testudo graeca. (C) Splitting of vertebral scute (arrow) in Testudo graeca. (D) Splitting of vertebral scutes (arrows) with misshapen adjacent vertebral scutes in Trachemys scripta (from Moustakas-Verho et al., 2014). (E) Splitting of vertebral scutes (arrows), supernumerary vertebral scute (asterisk), and absence of costal scute on right (3 scutes, rather than 4 , labeled in white) in Testudo graeca (from Cherepanov, 2014).

Proganochelys from the Triassic of Germany (Gaffney, '90), display the same pholidosis character as modern forms. The phylogenetic conservatism of turtle scutes, however, looks paradoxical in comparison with their individual instability. Turtles show extremely wide individual variability of the scute mosaic in both the number and frequency of anomalies. Thousands of abnormal individuals of turtles belonging to almost all extant and many extinct species have been described (Gadow, '99; Parker, '01; Newman, '05; Coker, '10; Deraniyagala, '36; Lynn, '37; Zangerl and Johnson, '57; Ewert, '79; Pritchard, '79; Mast and Carr, '89; Bujes and Verrastro, 2007; CorderoRivero et al., 2008; Ergene et al., 2011). In natural populations the proportion of turtles with an atypical arrangement of the scute mosaic may be up to $70 \%$ in the common European pond tortoise Emys orbicularis (Cordero-Rivero et al., 2008). The extremely high variability of pattern is demonstrated by the olive loggerhead Lepidochelys olivacea: the number of scutes in its carapace is so unstable that it is impossible to determine the typical number of scutes (Pritchard, '79).

Attempts to explain the high individual variation of scutes in turtles have been undertaken repeatedly. An extravagant idea was proposed by Gadow ('99): he believed that young individuals of marine turtles (in his opinion, Caretta caretta) usually have a greater number of scutes than older individuals of the same species. Based on this assumption, the author proposed that, during ontogeny the number of scutes gradually decreases until the typical number is reached. In Gadow's opinion, reduction is realized by the fusion or suppression of scutes, and each succeeding stage is strictly connected with the previous. Thus, transformations of scute mosaic strictly follow a certain trend, i.e., they are orthogenetic. Further studies have revealed the inconsistency of the orthogenetic concept. First, the newborns examined by Gadow were incorrectly referred to as $C$. caretta, and actually belonged to another species, Lepidochelys olivacea (see
Pritchard, 2007), which show extremely unstable scutation (see above). Second, the study of more individuals of $C$. caretta (Coker, '05, '10) has not revealed distinctions in the number of scutes among young and old individuals.

Disturbances resulting in scute anomalies do, however, occur during embryogenesis. Several researchers believe that they are connected with environmental factors during incubation. Environmental factors hypothesized to contribute to the development of scute anomalies include mechanical stresses (Yntema, '70), such as those produced by desiccation (Coker, '10), high temperature (Lynn and Ullrich, '50), and environmental pollution (Bujes and Verrastro, 2007). However, some anomalies are considered to be of a genetic nature (Zangerl and Johnson, '57). Zangerl ('69) recognized two types of anomalous scute variations. The first comprise "rare abnormities of ontogeny," deviations that appear to be the "result of accidents during early ontogenetic development (teratological features) or injury anytime during ontogeny)." The second are "repetitive anomalies," i.e., symmetrical and asymmetrical variants appearing with definite frequencies for each species or genus that presumably represent a phenotypic expression of genotypic variability. Newman ('05) considered this regularity of scute anomalies to be a systematic atavism that could be used to diagnose chelonian species. Thus, all anomalies were divided into nonhereditary and hereditary, although genetic control of the latter was hypothetical.

Attempts to separate the genetic component of variation from the effect of external factors have not been successful. What has been shown is that particular turtle populations differ in the frequency of abnormal individuals. These distinctions are connected to differences in the extent of resistance of these populations to adverse environmental factors, which (the extent of resistance) is possibly under genetic control (CorderoRivero et al., 2008; Velo-Anton et al., 2011). However, genetic determination of anomalies is not corroborated with certainty. 
Scute anomalies are subdivided into three main types: (i) atypical shape or size of scutes, (ii) presence of supernumerary scutes, and (iii) absence of some regular scutes (Fig. 5). These types of anomalies occur separately or together in the same individual. Among abnormal turtles, asymmetrical variants prevail. Scute aberrations occur in all regions of the carapace or plastron, but the most variable region is the posterior part of the carapace. The most common aberrant variant is the presence of additional scutes (Zangerl and Johnson, '57; Ewert, '79; Mast and Carr, '89; Bujes and Verrastro, 2007; Cordero-Rivero et al., 2008).

We have hypothesized that the symmetrical and asymmetrical anomalies in the vertebral and costal scutes (possibly also plastral scutes) is strongly influenced by the presence of "vacant" septal depressions that, in normal turtles, are free from scute anlagen (Cherepanov, '89, 2005, 2014). This would explain why the most frequent type of anomaly is the presence of additional scutes. Experimental data and our mathematical model of scute formation corroborate this hypothesis and furthermore would suggest that, as hypothesized for natural variation, changing the distance between scute primordia could lead to the formation of supernumerary scutes (Moustakas-Verho et al., 2014). Abnormal growth or a shift in reaction-diffusion dynamics could alter the relative distances of forming scute primordia, resulting in "vacant" areas where supernumerary primordia could form.

Aberrations of vertebral and costal scutes have traditionally attracted attention. These are frequently anomalies of the "zigzag" type (Pritchard, 2007), an asymmetrical arrangement of the left and right costal scutes with paired (unfused) asymmetrical triangular vertebral scutes wedging between them (Fig. 5). This type of anomaly shows a certain regularity in the arrangement of scutes (Coker, '10; Zangerl and Johnson, '57; Ewert, '79), suggesting that vertebral and costal scutes might not be independent developmental modules. Researchers have hypothesized that in the case of abnormal development of pholidosis, the shape of neighboring scutes changes as a result of compensatory growth combined with the preservation of general shell configuration (Zangerl and Johnson, '57; Pritchard, 2007). The phenomenon of regularity of abnormal scutes of the carapace was named the "dovetail syndrome” (Ewert, '79). According to Ewert, in dovetail syndrome "the pleural (=costal) series become less and less symmetrical posteriorly, so much so that posterior vertebral scutes appear to have merged indistinguishable with pleurals from a given side" (Ewert, '79), and the vertebral series is quite often paired.

Are the carapace and plastron independent structures evolutionarily, developmentally, and/or functionally? In terms of scutes, there are no turtles currently known to have scutes on the carapace but not the plastron (and vice versa; Lyson et al., 2014). However, the patterning of the carapacial scutes appears to be independent of the patterning of the plastral scutes (and vice versa). From extensive data on individual variation (Newman,
'05; Zangerl and Johnson, '57; Cordero-Rivero et al., 2008), we see that the scutes of the plastron are less variable than the carapace, and the frequency of anomalies is considerably lower. Anomalies seen in the carapace are also usually not accompanied by teratogenic changes in the plastron (Cherepanov, 2005, 2014). The lower variability in the pattern of the scutes of the plastron may be related to complexity: six pairs of units arranged in two columns is a system with fewer components than the carapace, and, therefore, should be more stable.

\section{CONCLUSIONS}

The developmental differences observed and hypothesized to be important for the morphological diversity of the turtle epidermis provide a basis for future investigations. Turtle scutes, like feathers, are generally thought to have been derived from the reptilian scale (Maderson, '72). Turtle scutes share some genetic and cellular mechanisms with other reptilian epidermal derivatives, and could be homologous at some level sensu Van Valen's continuity of information ('82). However, shared mechanisms among developmental precursors does not necessarily equate to a homology of adult characters (Wagner and Gauthier, '99). Scutes are a basal trait in extant turtles, as they were present on both Odontochelys and Proganochelys (Gaffney, '90; Lyson et al., 2014). Because turtle shell development begins with the formation of the $\mathrm{CR}$, even in species where the dermal components of the carapace are reduced, we propose that a modification to the developmental program of scales occured with the evolution of the CR and the shell. We argue that scutes share some elements of their developmental program with scales and other ectodermal organs, but are in a new anatomical location on the shell with a modified mode of growth; therefore, we consider scutes to be an evolutionary novelty. The tubercles found on turtle shells have been hypothesized to be homologous to scales found on the limbs of turtles, as their histological development is indistinguishable (Cherepanov, '85, '92, 2005). Tubercles are, therefore, a common feature of reptiles, unlike scutes, which are a unique formation of epidermis.

\section{ACKNOWLEDGMENTS}

The authors would like to thank St. Petersburg State University for a research grant, no. 0.38.292.2015, and the Academy of Finland for support.

\section{LITERATURE CITED}

Alibardi L. 1996. Scale morphogenesis during embryonic development in the lizard Anolis lineatopus. J Anat 188:713-725.

Alibardi L. 2002. Immunocytochemical observation on the cornification of soft and hard epidermis in the turtle Chrysemys picta. Zoology 105:31-44.

Alibardi L, Minelli D. 2014. Sites of cell proliferation during scute morphogenesis in turtle and alligator are different from those of lepidosaurian scales. Acta Zoologica 0:1-15. DOI: 10.1111/azo.12114 
Alibardi L, Thompson MB. 1999. Morphogenesis of shell and scutes in the turtle Emydura macquarii. Aust J Zool 47:245-260.

Baden HP, Maderson PFA. 1970. Morphological and biophysical identification of fibrous proteins in the amniote epidermis. J Exp Zool 174:225-232.

Bujes CS, Verrastro L. 2007. Supernumerary epidermal shields and carapace variation in Orbigny's slider turtles, Trachemys dorbigni (Testudines, Emydidae). Rev Bras Zool Curitiba 24:1-10.

Burke AC. 1989. Development of the turtle carapace: implications for the evolution of a novel bauplan. J Morphol 199:363-378.

Cherepanov G0. 1985. Development of the horny shell in Testudo graeca. Vestnik Leningrad Univ Biol 3:22-28.

Cherepanov G0. 1989. New morphogenetic data on the turtle shell: discussion on the origin of the horny and bony parts. Studia Geologica Salmanticensia. Studia Palaeocheloniologica 3:9-24.

Cherepanov G0. 1992. Development of the carapace skin in Trionyx sinensis (Testudinata). Zool Zhurnal 71:128-133.

Cherepanov G0. 2002. Pholidosis of the turtle shell in onto- and phylogenesis. Zool Zhurnal 81:480-488.

Cherepanov G0. 2005. Turtle shell: morphogenesis and evolution. St Petersburg: .

Cherepanov G0. 2006. Ontogenesis and evolution of horny parts of the turtle shell. Fossil Turtle Research. Suppl Russ J Herpetol 1:1933.

Cherepanov G0. 2014. Patterns of scute development in turtle shell: symmetry and asymmetry. Paleontol J 48:1275-1283.

Coker R. 1905. Gadow's hypothesis of "orthogenetic" variation in Chelonia. Johns Hopkins Univ Circ 24:9-24.

Coker R. 1910. Diversity in the scutes of Chelonia. J Morphol 21:1-75.

Cordero-Rivera A, Ayres Fernandez C, Velo-Anto G. 2008. High prevalence of accessory scutes and anomalies in Iberian populations of Emys orbicularis. Rev Esp Herpetol 22:5-14.

Crawford NG, Parham JF, Sellas AB, et al. 2014. A phylogenomic analysis of turtles. Mol Phylogenet Evol DOI: 10.1016/j. ympev.2014.10.021

DeBraga M, Rieppel 0. 1997. Reptile phylogeny and the interrelationships of turtles. Zool J Linn Soc 120:281-354.

Deraniyagala PEP. 1936. Some postnatal changes in the leathery turtle Dermochelys coriaceae. Ceylon J Sci Ser B 19:225-239.

Ergene S, Aymak C, Ucar AH. 2011. Carapacial scute variation in green turtle (Chelonia mydas) and loggerhead turtle (Caretta caretta) hatchlings in Alata, Mersin, Turkey. Turk J Zool 35:343-356.

Ewert MA. 1979. The embryo and its egg: development and natural history. In: Harless M, Morlock H, editors. Turtles, perspectives and research. New York: John Wiley \& Sons. p 333-413.

Gadow H. 1899. Orthogenetic variations in the shell of Chelonia. In: Willey A, editor. Zoological results based on material from New Britain, New Guinea, Loyalty Islands and elsewhere, collected during the Years 1895, 1896, and 1897. Cambridge: University Press. 3: 207-222.

Gaffney ES. 1990. The comparative osteology of the Triassic turtle Proganochelys. Bull Am Mus Natur Hist 194:1-263.
Gauthier J, Kluge AG, Rowe T. 1988. The early evolution of the Amniota. In: Benton MJ, editor. The Phylogeny and Classification of the Tetrapods. Oxford: Clarendon Press. p 103-155.

Gierer A, Meinhardt H. 1972. A theory of biological pattern formation. Kybernetik 12:30-39.

Goette A. 1899. Über die Entvicklung des knöchernen Ruckenschildes (Carapax) der Schildkröten. Z wiss Zool 66:407-434.

Guyot G, Pieau C, Renous S. 1994. Developpement embryonnaire d'une tortue terrestre, la tortue d' Hermann, Testudo hermanni Gmelin, 1789. Ann Sci Nat Zool Paris 15:115-137.

Harris MP, Fallon JF, Prum RO. 2002. Shh-Bmp2 signaling module and the evolutionary origin and diversification of feathers. J Exp Zool (Mol Dev Evol) 294:160-176.

Hirasawa T, Nagashima H, Kuratani S. 2013. The endoskeletal origin of the turtle carapace. Nat Commun 4:2107.

Jernvall J, Thesleff I. 2000. Reiterative signaling and patterning during mammalian tooth morphogenesis. Mech Dev 92:19-29.

Lange . 1931. Integument der Sauropsiden. Handbuch der vergleichenden Anatomie der Wirbeltiere 1:375-448.

Laurin M, Reisz RR. 1995. A reevaluation of early amniote phylogeny. Zool J Linn Soc 113:165-223.

Lee MSY. 1997. Pareiasaur phylogeny and the origin of turtles. Zool J Linn Soc 120:197-280.

Lynn WG. 1937. Variation in scutes and plates in the box-turtle, Terrapene carolina. Am Nat 71:421-426.

Lynn WG, Ullrich SMC. 1950. Experimental production of shell abnormalities in turtles. Copeia 4:253-262.

Lyson TR, Bever GS, Scheyer TM, Hsiang AY, Gauthier JA. 2013. Evolutionary Origin of the Turtle Shell. Curr Biol 23:1113-1119.

Lyson TR, Schachner ER, Botha-Brink J, et al. 2014. Origin of the unique ventilatory apparatus of turtles. Nat Commun 5:5211.

Maderson PFA. 1965. The embryonic development of the squamate integument. Acta Zool 46:275-295.

Maderson PFA. 1972. When? Why? and How?: some speculations on the evolution of the vertebrate integument. Am Zool 22:159171.

Maderson PFA. 1985. Some developmental problems of the reptilian integument. Biology of the reptilia. New York: John Wiley. 14: p 524-598.

Mast RB, Carr JL. 1989. Carapacial scute variation in Kemp's ridley sea turtle (Lepidochelys kempi) hatchlings and juveniles. In: Caillouet $\mathrm{CW}$, Landry AM, editors. Proceedings of the first international symposium on Kemp's Ridley sea turtle biology, conservation and management. p 202-219.

Moustakas JE. 2008. Development of the carapacial ridge: implications for the evolution of genetic networks in turtle shell development. Evol Dev 10:29-36.

Moustakas-Verho JE, Zimm R, Cebra-Thomas J, et al. 2014. The origin and loss of periodic patterning in the turtle shell. Development 141:3033-3039.

Newman HH. 1905. The significance of scute and plate "abnormalities" in Chelonia. Biol Bul 10:68-114. 
Obst FJ. 1986. Turtles, Tortoises and Terrapins. Edition Leipzig.

Parker GH. 1901. Correlated abnormalities in the scutes any bony plates of the carapace of the sculptured tortoise. Am Nat 35: 17-24.

Pispa J, Thesleff I. 2003. Mechanisms of ectodermal organogenesis. Dev Biol 262:195-205.

Pritchard PCH. 1979. Encyclopedia of turtles. Hong-Kong: TFH Publ, Inc.

Pritchard PCH. 2007. Evolution and structure of the turtle shell. In: Wyneken J, Godfrey MH, Bels V, editors. Biology of turtles. Boca Raton-London-New York: CRC Press. p 45-84.

Reisz RR, Laurin M. 1991. Owenetta and the origin of turtles. Nature 349:324-326.

Rieppel 0, Reisz RR. 1999. The origin and early evolution of turtles. Annu Rev Ecol Syst 30:1-22.

Ruckes H. 1929. The morphological relationships between the girdles, ribs and carapace. Ann N Y Acad Sci 73:81-120.

Sawyer RH. 1972. Avian scale development. I. Histogenesis and morphogenesis of the epidermis and dermis during formation of the scale ridge. J Exp Zool 181:365-383.

Shaffer HB. 2013. The western painted turtle genome, a model for the evolution of extreme physiological adaptations in a slowly evolving lineage. Genome Biol 14:R28.
Thomson RC, Plachetzki DC, Mahler DL, Moore BR. 2014. A critical appraisal of the use of microRNA data in phylogenetics. PNAS 111: E3659-E3668.

Van Valen L. 1982. Homology and causes. J Morphol 173:305-312.

Velo-Anton G, Becker CG, Cordero-Rivera A. 2011. Turtle carapace anomalies: the roles of genetic diversity and environment. PLOS ONE 6:1-11.

Wagner GP, Gauthier JA. 1999. 1,2,3=2,3,4: a solution to the problem of the homology of the digits in the avian hand. PNAS 96:51115116.

Wang Z. 2013. The draft genomes of soft-shell turtle and green sea turtle yield insights into the development and evolution of the turtle-specific body plan. Nat Genet 45:701-706.

Webb RG. 1962. North American recent soft-shelled turtles (Family Trionychidae). University of Kansas.

Yntema CL. 1968. A series of stages in the embryonic development of Chelydra serpentine. J Morphol 125:219-251.

Yntema CL. 1970. Extirpation experiments on embryonic rudiments of the carapace of Chelydra serpentine. J Morphol 132:235-244.

Zangerl R. 1969. The turtle shell. In: Gans C, Bellairs d'A, Parsons T, editors. Biology of reptilia, I. New York: Acad Press. p 311-339.

Zangerl R, Johnson RG. 1957. The nature of shield abnormalities in the turtle shell. Fieldiana, Ser Geol 10:341-362. 